\title{
STIGMATIZATION OF PEOPLE WITH ALCOHOL DEPENDENCE COMPARED TO PEOPLE WITH SCHIZOPHRENIA
}

\author{
Jana Serebriakova, \& Maria Hildegard Walter \\ Department of Psychology, University of Innsbruck (Austria)
}

\begin{abstract}
Previous stigma research has shown considerable differences between various disorders. However, most studies neglected the impact on stigmatization that behaviour, diagnosis and the label as a disease have separated from each other. To counteract this limitation we examined differences in public conceptions of the most stigmatized mental illnesses: alcohol dependence and schizophrenia.

We analysed responses to vignettes describing individuals meeting DSM-III-R criteria for alcohol dependence and schizophrenia, without mentioning the name of the disease. The purpose is to explore whether there are differences regarding 1) the stigma, containing personal attributes (stereotypes), emotional reactions (prejudices) and social distance (discrimination), 2) the impact of labelling the behaviour in the vignette as a disease, and 3) the impact of giving the right diagnosis.

We found differences of stigmatization between alcohol dependence and schizophrenia. Contrary to previous research, labelling the behaviour in the vignettes as a disease has a positive impact on stigmatization towards people with alcohol dependence and schizophrenia. One of the most notable differences between the two disorders is that, regarding alcohol dependence, giving the right diagnosis affects all components of stigma negatively, while giving the diagnosis schizophrenia shows less negative reactions.

Our findings illustrate the need for differentiation between mental disorders as well as between the different components of stigma. Moreover, labelling with a disease or diagnosis has a various influence on stigmatization between alcohol dependence and schizophrenia. The described differences of public conceptions have important implications for the planning of anti-stigma programs and may help developing more customized interventions.
\end{abstract}

Keywords: Stigmatization, alcohol dependence, addiction, schizophrenia.

\section{Introduction}

A considerable part of stigma research in psychiatry has dealt with mental disorder in general. However, previous research has shown considerable differences between various mental disorders (Aydin \& Fritsch, 2015). Therefore, a systematic comparison between lay beliefs, attitudes and reactions to those suffering from alcohol dependence and schizophrenia, will be provided. The public stigma has relevant consequences for the stigmatized (Anagnostopoulos \& Hantzi, 2011). Perceptions of public stigma can conduce to the experience of self-stigma, which influences seeking professional help (Schomerus, 2009). Furthermore, it has negative effects on quality of treatments, process of the disease, integration and quality of life for the stigmatized (Meise, Fleischhacker \& Schöny, 2002).

In psychiatric attitude research, the stigma of alcohol dependence received less attention than the stigma of other mental disorders (Schomerus et al., 2010). Previous studies showed that people with alcohol dependence are more stigmatized than people with schizophrenia (Pescosolido et al., 2010). As reported in previous studies, the public appears somewhat more likely to identify symptoms of schizophrenia as an indication of mental disorder than symptoms of alcohol dependence. Furthermore, alcohol dependence is also considered as an infringement of social norms (Schomerus et al., 2011). In a review of studies, Link et al. (1987) showed that although most studies found some effects of labelling mental illness, but these effects were either not significant across all the outcomes or didn't hint towards more severe labels leading to more severe rejection. 


\section{Objectives}

Alcohol dependence and schizophrenia appear to be the most stigmatized mental disorders and should be main targets of interventions aimed at reducing the stigma of mental illness (Pescosolido et al., 2010). A better differentiation of the stigma components of these two disorders may allow us to develop more customized interventions that may prove more successful than broad and unspecific approaches.

Therefore, in our study similarities and differences will be examined regarding 1) the stigma, containing personal attributes (stereotypes), emotional reactions (prejudices) and the desire for social distance (discrimination), 2) the impact of labelling the behaviour in the vignette as a disease, and 3) the impact of giving the right diagnosis.

\section{Methods}

\subsection{Design and sample}

The sample consisted of 637 German-speaking participants (70 per cent female). Participants were aged 16 to 71 years $(\mathrm{M}=25.5, \mathrm{SD}=7.9)$.

The presented study was conducted as an online survey targeting German-speaking participants between February and March 2017. We placed advertisements in the mailing list of the university and Facebook-posts. Participation was voluntary and included electronically obtained underwriting of their anonymity for all participants at the beginning of the survey. To avoid bias, we told the participants in the beginning that we consider the attitude, but did not mention that the survey is about attitude toward mental disorders. During the survey, participants obtained two vignettes containing a diagnostically unlabeled psychiatric case history and filled out questionnaires measured personal attributes, emotional reactions and social distance towards the persons described in the vignettes, two questions about the labelling of the problem in the vignettes and questionnaires on socio-demographic details.

\subsection{Instruments}

Vignette. The survey began with the presentation of a vignette containing a diagnostically unlabeled psychiatric case history. The case histories either represented a case of alcohol dependence or schizophrenia. Angermeyer and Matschinger (2003a) used DSM-III-R criteria for the construction of the vignettes, but the symptoms in the vignettes also fulfilled the current criteria of ICD-10 for the respective disorder. The samples were presented with both vignettes.

Personal attributes. A list of nine personal attributes was created by Angermeyer (2003b) to cover two important components of the stereotype of mental illness: dangerousness and dependency. Respondents were asked to indicate on a five-point Likert scale ranging from "definitely true" to "definitely not true" to what extent these attributes apply to the person described in the vignette.

Emotional reactions. A list of eleven five-point Likert-scaled items $(1=$ definitely the case, $5=$ definitely not the case), representing three ways to respond to individuals with mental illness (fearful, adverse and prosocial emotions), was used to assess the respondents' emotional reactions to the person described in the vignette (Sulzenbacher, 2004).

Social distance. For the assessment of respondent's desire for social distance, we used a scale developed by Matschinger, Rost and Angermeyer (2000). It includes seven items representing the following social relationships: rent a room, commonplace of work, neighborhood, member of the same social circle, personal job brokering, marriage into one's family and child care. Answers, to what extent they would, in those situations, accept the person described in the vignette, were given on a five-point Likert scale offering choices from "most certainly" to "certainly not".

Labelling. The respondents were asked, if they would indicate the problem described in the vignette as a disease. If they answer in the affirmative, we used an open-ended question to indicate the diagnosis of the disease. Two main categories were distinguished: correct and incorrect diagnosis.

\section{Discussion}

Summarizing our findings, a number of differences between alcohol dependence and schizophrenia emerge. While the person in the alcohol dependence-vignette elicits a greater desire for social distance, more emotions that are adverse and less prosocial emotions, the person in the schizophrenia-vignette was frequently perceived as more dangerous and dependent as well as elicits more emotions that are fearful. The symptoms of both disorders in the vignette are identified as an indication of a disease by the majority of the respondents. Contrary to previous research (Angermeyer \& Matschinger, 2003a), labelling the behavior in the vignettes as a disease has a positive impact on stigmatization towards people with alcohol dependence and schizophrenia. People, who label the described problem in the 
vignette as a disease, perceive in both cases more prosocial emotions and perceive the person in the vignette as more dependent. In the alcohol dependence-vignette, they furthermore perceive less adverse emotions, than people, who did not label the problem in the vignette as a disease. It seems like the label has a protective mechanism toward stigmatization. One of the most notable differences between the two disorders is that, regarding alcohol dependence, giving the right diagnosis affects all components of stigma negatively, while giving the diagnosis schizophrenia shows fewer negative reactions. In the case of alcohol dependence, giving the individual in the vignette the right diagnosis has negative effects on the reactions towards them (greater desire for social distance, adverse emotions and perception as dangerous). By contrast, in the case of schizophrenia, giving the right diagnosis only has a negative effect on the perceived danger. The differences in the case of alcohol dependence could be resulted from the fact that alcohol dependence is seen as a disease, a weakness of will as well as an infringement of social norms.

Those described differences of public conceptions have important implications for the planning of anti-stigma programs, because they show that there are no homogenous and over all mental disorders generalizable anti-stigma strategies. Therefore, it should be the main target to develop more customized interventions, based on the differences across various mental disorders.

\section{Conclusions}

Our findings illustrate the need for differentiation between mental disorders as well as between the different components of stigma. Moreover, labelling with a disease or diagnosis has various influence on stigmatization between alcohol dependence and schizophrenia. The described differences of public conceptions have important implications for the planning of anti-stigma programs and may help developing more customized interventions.

\section{References}

Anagnostopoulos, F., \& Hantzi, A. (2011). Familiarity with and Social Distance from People with Mental Illness: Testing the Mediating Effects of Prejudiced Attitudes. Journal of Community \& Applied Social Psychology, 21(5), 451-460.

Angermeyer, M. C., \& Matschinger, H. (2003a). The stigma of mental illness: effects of labelling on public attitudes towards people with mental disorder. Acta Psychiatrica Scandinavia, 108(4), 304-309.

Angermeyer M. C., \& Matschinger H. (2003b). Public beliefs about schizophrenia and depression: similarities and differences. Social Psychiatry and Psychiatric Epidemiology, 38(9), 526-534.

Aydin, N., \& Fritsch, K. (2015). Stigma und Stigmatisierung von psychischen Krankheiten. [Stigma and stigmatization of mental disorders]. Psychotherapeut, 60(3), 245-257.

Link, B. G., Cullen, F. T., Frank, J., \& Wozniak, J. F. (1987). The social rejection of former mental patients. Understanding why labels matter. American Journal of Sociology, 92(6), 1461-1500.

Matschinger, H., Rost, J., \& Angermeyer, M. C. (2000). Probleme der Populationsheterogenität bei der Messung und Erklärung von Einstellungsdimensionen. Darstellung am Beispiel sozialer Distanz gegenüber psychisch Erkrankten. [Problems of the population-heterogeneity at the measurement and explanation of attitude-dimensions. Illustration using the example of social distance toward people with mental disorders]. In Reinecke, J., \& Tarnei, C. (Eds.), Angewandte Klassifikationsanalyse in den Sozialwissenschaften (pp. 159-177). Münster: Waxmann.

Meise, U., Fleischhacker, W.W., \& Schöny, W. (2002). Es ist leichter ein Atom zu zerstören, als ein Vorurteil. [It is easier to destroy an atom than a prejudice]. Neuropsychiatrie, 16(1-2),1-4.

Pescosolido, B. A., Martin, J. K., Long, J. S., Medina, T. R., Phelan, J. C., \& Link, B. G. (2010). “A Disease Like Any Other"? A Decade of Change in Public Reactions to Schizophrenia, Depression, and Alcohol Dependence. The American Journal of Psychiatry, 167(11), 1321-1330.

Schomerus, G. (2009). Steine auf dem Weg. Stigma und Hilfesuchverhalten. [Stones on the way. Stigma and seeking help behavior]. Psychiatrische Praxis, 36(2), 53-54.

Schomerus, G., Holzinger, A., Matschinger, H., Lucht, M., \& Angermeyer, M. C. (2010). Public attitudes towards alcohol dependence. Psychiatrische Praxis, 37(3), 111-118.

Schomerus, G., Lucht, M., Holzinger, A., Matschinger, H., Carta, M. G., \& Angermeyer, M. C. (2011). The Stigma of Alcohol Dependence Compared with Other Mental Disorders: A Review of Population Studies. Alcohol and Alcoholism, 46(2), 105-112.

Sulzenbacher, H. (2004). Die Relevanz des Begriffs „Schizophrenie“für die soziale Einstellung zu schizophren Erkrankten: Eine Untersuchung bei Studierenden [The relevance of the concept "Schizophrenia" for the social attitude toward schizophrenic people]. (Unpublished doctoral dissertation). Leopold-Franzens-Universität, Innsbruck, AUT. 